\title{
Radiographically occult lung cancer treated with fibreoptic bronchoscopic electrocautery: a pilot study of a simple and inexpensive technique
}

\author{
T.J. van Boxem*, B.J. Venmans*, F.M. Schramel*, J.C. van Mourik**, R.P. Golding+, \\ P.E. Postmus*, T.G. Sutedja*
}

Radiographically occult lung cancer treated with fibreoptic bronchoscopic electrocautery: a pilot study of a simple and inexpensive technique. T.J. van Boxem, B.J. Venmans, F.M. Schramel, J.C. van Mourik, R.P. Golding, P.E. Postmus, T.G. Sutedja. CERS Journals Ltd 1998.

ABSTRACT: The curative potential of bronchoscopic intervention, e.g. photodynamic therapy (PDT) and brachytherapy, for resectable radiographically occult lung cancer has been reported previously. Bronchoscopic electrocautery is currently feasible using an insulated flexible bronchoscope to coagulate and vaporize tumour tissue. Since the lesions are usually small, noninvasive bronchoscopic electrocautery may be able to eradicate radiographically occult lung cancer completely.

In a prospective study, 13 patients with 15 radiographically occult lung cancer lesions were treated with bronchoscopic electrocautery. The duration of follow-up was $\mathbf{S} 16$ months. The median age of the patients was 69 yrs (range 48-79 yrs). Fibreoptic bronchoscopy under local anaesthesia was used to coagulate the occult lung cancer. Approximately $30 \mathrm{~W}$ of energy was applied until visible necrosis of the tumour area became apparent. There were no immediate complications.

In 10 patients with 12 lesions, a complete response $(C R)$ was obtained (CR rate $80 \% ; 95 \%$ confidence interval $(95 \%$ CI) $52-96 \%)$. Median duration of follow-up was 21 months (range 16-43 months). Bronchoscopic electrocautery did not obtain a CR in the remaining three patients, but PDT also failed to achieve CR. Two patients underwent radical resection, and the tumours were histologically confirmed to be more invasive. One patient received external radiotherapy. Three patients with a CR died during follow-up, two as a result of myocardial infarction and apoplexy, and one because of metastasis from his previously resected T3N1 primary large cell cancer.

Current data show bronchoscopic electrocautery to be equally effective and potentially as curative as photodynamic therapy for treating patients with radiographically occult lung cancer. Obvious advantages are that it is an inexpensive and simple procedure, which does not cause photosensitivity.

Eur Respir J 1998; 11: 169-172.
Depts of *Pulmonary Medicine, **Radiology and +Surgery, Free University Hospital, Amsterdam, The Netherlands.

Correspondence: G. Sutedja

Dept of Pulmonary Medicine

Free University Hospital

PO Box 7057

1007 MB Amsterdam

The Netherlands

Fax: 0031204444328

Keywords: Bronchoscopic electrocautery occult lung cancer

Received: January 301997

Accepted after revision September 281997
Radiographically occult lung cancer (ROLC) is a wellknown clinical problem. In several studies, it has been shown that photodynamic therapy (PDT) is an effective treatment modality for these patients [1-4]. Based on these favourable long-term results, it has been proposed as primary treatment for these lesions [5, 6]. High dose rate brachytherapy was used for the same category of patients, showing its curative potential [7, 8]. Both PDT and brachytherapy facilities are costly if used only for the relatively small number of patients with ROLC. A much less expensive method to obtain tissue necrosis is electrocautery. Bronchoscopic electrocautery (BE) is the endoscopic use of a high frequency electrical current for the destruction of tissue [9]. Heat is generated due to tissue resistance. Electrocautery equipment is available in every surgical ward and has been a standard tool during surgical and endoscopic procedures [10]. The extent of BE necrosis depends on: the voltage setting; the duration of contact between electrode and tissue; and tissue density or moisture in the presence of blood or mucus $[9,10]$.

As early as 1984, it was reported that BE, using either a rigid or fibreoptic bronchoscope (FOB), resulted in tissue necrosis several millimetres deep and could also be used to debulk intraluminal tumour for rapid palliation [11-13]. Tissue necrosis several millimetres deep [11] may be sufficient for cure of ROLC. We conducted a prospective study in patients with ROLC using electrocautery, followed by PDT in the event of failure. Surgery was performed if tumour persisted in patients with resectable tumour.

\section{Methods}

Consecutive patients, referred to our hospital by pulmonologists for intraluminal treatment of ROLC, were included if tumours were $\partial 1 \mathrm{~cm}^{2}$ as confirmed by several 
separate histological biopsies in areas proximal and distal to the visible tumour margins [2]. High-resolution computed tomography (HRCT) scans were performed prior to BE to include only those with strict intraluminal tumours [14]. Patients with failure of previous intraluminal treatment with PDT were also included. BE was performed under topical anaesthesia, as described previously [13]. Tumour dimensions were assessed bronchoscopically and documented photographically. Biopsies were reviewed to confirm malignancy. Approximately $30 \mathrm{~W}$ of energy was applied under bronchoscopic control until coagulation became visible. A marginal area of $0.5 \mathrm{~cm}$ normal mucosa around $ð 1 \mathrm{~cm}^{2}$ tumours was also coagulated.

A complete response (CR) was achieved if multiple biopsies and brushes were negative during follow-up FOB and if chest radiographs or repeat HRCT, in case of doubt, remained normal. Patients not achieving a CR and not previously treated with PDT were subsequently treated with PDT using $2 \mathrm{mg} \cdot \mathrm{kg}^{-1}$ Photofrin IIß) (QLT Pharmaceuticals, Vancouver, Canada) injection and laser illumination $48 \mathrm{~h}$ thereafter [3]. Follow-up FOB was performed at 3-4 month intervals. In candidates for resection, follow-up FOB was performed several times during the first 3 months. When tumour persisted after both BE and PDT, surgical resection was performed without delay. This study protocol was approved by the Medical Ethics Committees of our hospital. All patients, including resection candidates, were given an extensive explanation and written information about the current protocol, its limitations and possible advantages. All subjects gave their informed consent before treatment. This study was not financially supported by any company, except for the free use of the insulated fibreoptic bronchoscope prototype of Olympus ${ }^{\circledR}$ (Tokyo, Japan) for electrocautery.

\section{Results}

Thirteen patients (12 males and one female), with 13 T1N0M0 (tumour, node, metastasis classification) squamous cell cancer and two carcinomas in situ, were treated and followed-up for at least 16 months. Patient characteristics are presented in table 1 . Five patients had resectable intraluminal tumours. There was no direct complication of BE. In all cases, visible coagulation of the tumour area was easily obtained. Two segmental bronchi showed slight stenosis after BE (patients Nos. 2 and 13; right bronchial (RB) segment number 6 and 8 localization, respectively). These complications were considered minor, did not cause symptoms and were left untreated. BE results are presented in table 1 and figure 1.

Two of the five patients with resectable lesions ultimately underwent radical lobectomies because of tumour persistence. In one of these subjects, PDT was not performed after BE because of tumour-positive biopsies distal to the initial tumour area during BE follow-up. Histological examinations showed tumours to be more invasive: in patient No. 3 the tumour diameter was $13 \mathrm{~mm}$, and in patient No. 5 minute infiltration of the deeper $(>4 \mathrm{~mm})$ submucosal bronchial glands was observed microscopically.

Three patients with $\mathrm{CR}$ died for reasons unrelated to their ROLC. In all three patients, follow-up bronchoscopy had been performed within 2 months prior to death, show-

Table 1. - Patient characteristics, tumour localization, resectability, BE response, post-BE treatment and followup

\begin{tabular}{|c|c|c|c|c|c|c|}
\hline $\begin{array}{l}\mathrm{Pt} \\
\text { No. }\end{array}$ & $\begin{array}{l}\text { Age } \\
\text { yrs }\end{array}$ & $\begin{array}{c}\text { Locali- } \\
\text { zation }\end{array}$ & $\begin{array}{l}\text { Resec- } \\
\text { table }\end{array}$ & $\begin{array}{c}\text { BE- } \\
\text { response }\end{array}$ & $\begin{array}{l}\text { Post-BE } \\
\text { treatment }\end{array}$ & $\begin{array}{c}\text { Follow-up } \\
\text { months }\end{array}$ \\
\hline 1 & 65 & LB1-2 & Yes & CR & - & 40 \\
\hline 2 & 72 & RB6 & No & $\mathrm{CR}$ & - & 17 \\
\hline 3 & 53 & LUL & Yes & PR & $\mathrm{S}$ & 16 \\
\hline 4 & 69 & RB $1-3$ & No & CR & - & $4 \dagger$ \\
\hline 5 & 68 & LUL & Yes & PR & PDT, S & 28 \\
\hline 6 & 73 & LUL & No & $\mathrm{CR}$ & - & $8^{\dagger}$ \\
\hline 7 & 79 & RML & No & $\mathrm{CR}$ & - & $11^{\dagger}$ \\
\hline 8 & 70 & RB3 & No & PR & PDT, RT & 21 \\
\hline 9 & 48 & LB6 & Yes & CR & - & 19 \\
\hline 10 & 78 & MC, LUL & No & $\mathrm{CR}$ & - & 20 \\
\hline 11 & 69 & LUL & Yes & CR & - & 13 \\
\hline 12 & 69 & RB2 & No & $\mathrm{CR}$ & - & 25 \\
\hline 13 & 72 & RB3, RB8 & No & CR & - & 19 \\
\hline
\end{tabular}

Pt: patient; LUL: left upper lobe; MC: main carina; ML: middle lobe; RLL: right lower lobe; LB6: left bronchial segment number 6; RB6: right bronchial segment number 6, etc.; BE: bronchoscopic electrocautery; CR/PR: complete/partial response; S: surgery; PDT: photodynamic therapy; RT: radiotherapy; ${ }^{\dagger}$ : death during follow-up unrelated to radiographically occult lung cancer.

13 patients with 15 lesions

$\downarrow$

CR: 10 patients

(12 lesions)

$\downarrow$ follow-up

3 deaths, unrelated to the occult lung cancer
2 treated with PDT $\rightarrow$ both PR $(\rightarrow 1$ radiotherapy and 1 \# surgery) and

$1^{\#}$ directly to surgery

Fig. 1. - Bronchoscopic electrocautery in occult lung cancers. \#: two patients with partial resection ultimately underwent radical lobectomies. The resected specimens showed tumours to be extraluminal 1.3 $\mathrm{cm}$ in diameter (patient No. 3) and deeper infiltration in the mucosal glands of the bronchial wall (patient No. 5). CR: complete resection; PDT: photodynamic therapy.

ing no tumour recurrence. In none of them was a postmortem examination obtained.

So far, seven patients with nine lesions are still in CR, with a median follow-up of 22 months (range 13-40 months). The CR rate of bronchoscopic electrocautery, including the three patients who died because of unrelated disease, is $80 \%$ (95\% CI 52-96\%).

\section{Discussion}

Various bronchoscopic techniques are available to palliate patients with obstructive lung tumours $[15,16]$. All these techniques have been shown to be effective in debulking intraluminal tumour. The curative potential of various bronchoscopic treatment methods in patients with strictly intraluminal tumour, such as occult lung cancer and carcinoma in situ, has been reported in several studies 
[1-8]. The most popular technique during the last decade has been PDT [1-6]. The photosensitizers used were considered to be tumour selective. However, data to support this drug selectivity are lacking, and skin photosensitivity remains a problem $[17,18]$. Brachytherapy has also been used with curative intent, albeit in functionally inoperable candidates [7]. Repeated treatments seem necessary, and issues regarding the optimal irradiation dose, dose fractionation, and normal tissue damage have not been resolved [8]. Compared to electrocautery, both PDT and brachytherapy equipment are more expensive, the procedures and logistics are more complex, and treatment effects are not immediately apparent. However, all bronchoscopic techniques lack the accuracy of assessing tumour depth, and treatment dosimetry remains difficult. Only empirical findings of visible tissue necrosis several millimetres thick are clear for the bronchoscopist. It is, therefore, fair to ask whether the treatment technique, as such, is important in obtaining complete responses in ROLC $[15,19]$.

Bronchoscopic electrocautery is a straightforward technique. The flexible probe allows gentle palpation and offers more manoeuvrability under visual control during the whole procedure. Local coagulation and haemostasis are easily achieved. Our previous data show that BE is a safe treatment for immediate palliation and is cost-effective $[13,20]$.

This study confirmed that the success of bronchoscopic treatment with curative intent is related to the exact dimension of the tumour. The limitations of radiographic criteria of ROLC have been discussed previously [14]. Histological studies in early surgical series in the past have shown the limitation of the so-called "x-ray occult" lung cancer, as only $68 \%$ of the tumours were truly occult [21]. It has also become clear that tumour dimension is related to nodal stage. Occult lung cancer $ð 3 \mathrm{~mm}$ thick and with a $20 \mathrm{~mm}$ longitudinal axis has been shown to be lymph node negative [22]. Consequently, several ongoing clinical trials with PDT have been using these criteria in resectable ROLC because nodal involvement precludes any bronchoscopic therapy with curative intent $[5,6]$. Hence, the strict eligibility criteria of PDT protocols for treating ROLC [2]. Reasons for failures of PDT in intraluminal stage I lung cancer have been analysed [3], and we recently reported that the criteria of HRCT findings should be included before embarking upon bronchoscopic treatment with curative intent [14]. Newer techniques, such as ultrasonography [7] and fluorescence endoscopy [23], may improve assessment of tumour dimension; however, their impact on the management of ROLC needs further study.

At the present time, the criteria of ROLC to be treated bronchoscopically with curative intent should consider the factors mentioned above. In this study, PDT also failed to obtain CR in two patients with tumour persistence after BE. Microscopic findings of the resected specimen underscore the limitations of ROLC criteria. These seem acceptable entirely for inoperable candidates. However, in patients with resectable lesions these criteria are not entirely perfect, despite the findings that they were indeed No [22]. The long-term complete responses after bronchoscopic treatment seem to justify the electrocautery approach in the majority of patients.

In conclusion, bronchoscopic electrocautery is an equally effective treatment with curative potential in patients with radiographically occult lung cancer, it is inexpensive and more easily applied than photodynamic therapy or brachytherapy. Randomized trials with longer follow-up are needed to explore its effects in radiographically occult lung cancer in candidates for resection.

\section{References}

1. Hayata Y, Kato H, Konaka C, et al. Photoradiation therapy with hematoporphyrin derivative in early and stage I lung cancer. Chest 1984; 86: 169-177.

2. Furuse K, Fukuoka M, Kato H, et al. The Japan Lung Cancer Photodynamic Therapy Study Group: a prospective phase II study on photodynamic therapy with photofrin II for centrally-located early-stage lung cancer. J Clin Oncol 1993; 11: 1852-1857.

3. Sutedja G, Lam S, LeRiche JC, Postmus PK. Response and pattern of failure after photodynamic therapy for intraluminal stage I lung cancer. J Bronchology 1994; 1: 295-298.

4. Dougherty TJ. Photodynamic therapy: new approaches. Semin Surg Oncol 1989; 5: 6-16.

5. Dougherty TJ. Photodynamic therapy for early stage lung cancer: preferable to resection? Chest 1992; 102: 13141315.

6. Edell ES, Cortese DA. Photodynamic therapy in the management of early superficial squamous cell carcinoma as an alternative to surgical resection. Chest 1992; 102: 1319_ 1322.

7. Ono R, Hirano H, Egawa S, Suemasu K. Bronchoscopic ultrasonography and brachytherapy in roentgenologically occult bronchogenic carcinoma. J Bronchology 1994; 1: 281-287.

8. Sutedja G, Baris G, van Zandwijk N, Postmus PK. Highdose rate brachytherapy has a curative potential in patients with intraluminal squamous cell lung cancer. Respiration 1993; 61: 167-168.

9. Jackson R. Basic principles of electrosurgery: a review. Can J Surg 1970; 13: 354-361.

10. Barlow DE. Endoscopic applications of electrosurgery: a review of basic principles. Gastrointest Endosc 1982; 14: 61-63.

11. Hooper RG, Jackson FN. Endobronchial electrocautery. Chest 1985; 87: 712-714.

12. Petrou M, Kaplan D, Goldstraw P. Bronchoscopic diathermy resection and stent insertion: a cost-effective treatment for tracheobronchial obstruction. Thorax 1993; 48: 1156-1159.

13. Sutedja G, van Kralingen K, Schramel F, Postmus PK. Fibreoptic bronchoscopy electrosurgery under local anesthesia for rapid palliation in patients with central airway malignancies: a preliminary report. Thorax 1994; 49: 1243-1246.

14. Sutedja G, Golding RP, Postmus PK. High resolution computed tomography in patients referred for intraluminal bronchoscopic therapy with curative intent. Eur Respir J 1996; 9: 1020-1023.

15. Sutedja G, Postmus PK. Bronchoscopic treatment of lung tumors: review article. Lung Cancer 1994; 11: 1-17.

16. Edell ES, Cortese DA, McDougall JC. Ancillary therapies in the management of lung cancer: photodynamic therapy, laser therapy and endobronchial prosthetic devices. Mayo Clin Proc 1993; 68: 685-690.

17. Braichotte DR, Wagnieres GA, Bays R, Monnier P, van den Bergh H. Clinical pharmacokinetic studies of Photo- 
frin by fluorescence spectroscopy in the oral cavity, the esophagus and the bronchi. Cancer 1995; 75: 27682778.

18. Dougherty TJ, Cooper MT, Mang TS. Cutaneous phototoxic occurrences in patients receiving Photofrin. Lasers Surg Med 1990; 10: 485-486.

19. Sutedja G, Schramel F, Postmus PK. Bronchoscopic treatment modalities in lung cancer, indications and limitations. Ann Oncol 1995; 6: 951-952.

20. Sutedja G, van Boxem T, Schramel F, van Felius C, Postmus PK. Endobronchial electrocautery is an excellent alternative for Nd:YAG laser to treat airway tumors. $J$ Bronchology 1997; 4: 101-105.
21. Woolner LB, Fontana RS, Cortese DA. Roentgenographically occult lung cancer: pathologic findings and frequency of multicentricity during a 10 year period. Mayo Clin Proc 1984; 59: 453-466.

22. Nagamoto N, Saito Y, Ohta S, et al. Relationship of lymph node metastasis to primary tumor size and microscopic appearance of roentgenographically occult lung cancer. Am J Surg Pathol 1989; 13: 1009-1013.

23. Lam S, MacAulay C, Hung J, LeRiche J, Profio AK, Palcic B. Detection of dysplasia and carcinoma in situ with a lung imaging fluorescence endoscope device. J Thorac Cardiovasc Surg 1993; 105: 1035-1040. 